\title{
Antibody-drug conjugates: smart weapons against cancer
}

Seyed Mohammad Gheibi Hayat ${ }^{1}$, Amirhossein Sahebkar ${ }^{2,3,4}$

${ }^{1}$ Department of Medical Genetics, School of Medicine, Shahid Sadoughi University of Medical Science, Yazd, Iran

Biotechnology Research Center, Pharmaceutical Technology Institute, Mashhad University of Medical Sciences, Mashhad, Iran

${ }^{3}$ Neurogenic Inflammation Research Center, Mashhad University of Medical Sciences, Mashhad, Iran

${ }^{4}$ School of Pharmacy, Mashhad University of Medical Sciences, Mashhad, Iran

Submitted: 7 March 2017

Accepted: 8 March 2017

Arch Med Sci 2020; 16 (5): 1257-1262

DOI: https://doi.org/10.5114/aoms.2019.83020

Copyright $\odot 2019$ Termedia \& Banach

The scientist Paul Ehrlich introduced the term 'magic bullet' for the first time. He envisioned that if a substance is capable of binding selectively to a pathogen, it might cause targeted drug delivery (toxin) to the pathogen by binding a toxic agent to this pathogen. He won the Nobel Prize in Medicine for this theory in 1908 [1-3].

Antibody-drug conjugates (ADCs) are a new class of drugs that have been designed to treat patients with cancer. ADCs are complex consisting an antibody and a drug (anticancer drug) that are connected to each other by a linker so that monoclonal antibodies in the Fab domain have paratopes dedicated to binding to the anticancer epitopes. Figure 1 depicts three components of ADCs [4, 5].

The ADC complex induces apoptosis in cancer cells in five stages.

First stage - cell surface binding: ADCs can bind to surface of cancer cells by binding of monoclonal antibody to its specific antigen (cancer antigen) and thus form the antigen-antibody complex.

Second stage - internalization: ADCs can be transported into cancer cells through receptor-mediated endocytosis.

Third stage - separation of antibody from drug: after endocytosis of ADCs into the cell, they are placed in primary vesicles and then by turning into secondary vesicles it results in disconnection of the linker and the drug is separated from the antibody.

Fourth stage - release: the drug is released into the cytoplasm.

Fifth stage - cell death: drugs can cause apoptosis in cancer cells through different mechanisms such as interaction with DNA, or inhibition of microtubules or enzymes involved in cell proliferation [6-8].

It is estimated that only about one percent of the ADCs can eventually find their way into the cancer cells, but even this small amount is more efficient than traditional treatments of cancer. One of the most important factors to increase endocytosis is choosing an appropriate epitope antigen for cancer. Affinity between antibodies and antigens plays an important role in increasing internalization of ADCs into the cancer cell. Internalization is performed via three mechanisms involving clathrin, caveolae or pinocytosis; the first and second mechanisms are receptor-mediated while the third one is receptor-independent.

Following endocytosis, ADCs are placed inside the primary vesicles of the cell and at the next stage turn into secondary vesicles after binding to lysosomes. The linker is disconnected due to low $\mathrm{pH}$ or the presence

\author{
Corresponding author: \\ Amirhossein Sahebkar \\ PharmD, PhD \\ Department of \\ Medical Biotechnology \\ School of Medicine \\ Mashhad University \\ of Medical Sciences \\ Mashhad, Iran \\ P.O. Box: 91779-48564 \\ Phone: +985118002288 \\ Fax: +98 5118002287 \\ E-mail: sahebkara@mums. \\ ac.ir, amir_saheb2000@ \\ yahoo.com
}




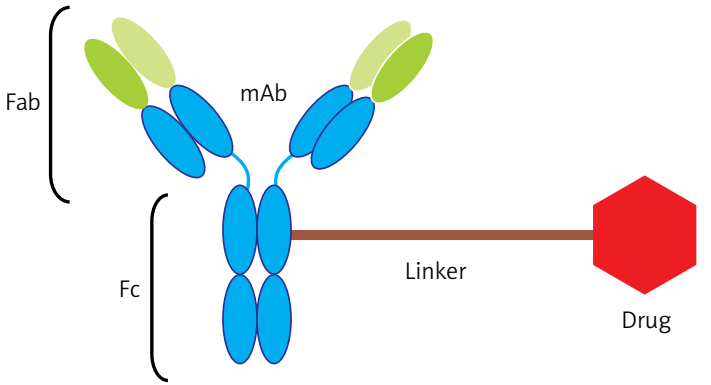

Figure 1. Components of an ADC complex

of cathepsin B, and then the antibody is separated from the drug [9-12]. The following discussion will be on some important factors that need to be considered in choosing the antibody, linker and drug.

$\operatorname{lgG} 1$ and $\operatorname{lgG} 3$ can activate the ADCC. IgG2 fixes the complement but not ADCC, and IgG4 is unable to do any of those actions. The most frequently used monoclonal antibodies are isotypes engineered from IgG1, IgG2 and IgG4. IgG3 isotype is not used due to the short half-life and allotypic polymorphism [13].

In the past, murine antibody was used to produce ADCs; but nowadays, regarding the human immune system response to this type of murine antibody, chimeric (65\% human derived), humanized (95\% human derived) or fully humanized (100\% human derived) antibodies (Figure 2) produced by phage display methods are being used. For choosing antibodies, biological activity of the Fc domain, which could interact with cells with the Fc receptor (FcRs), should be considered. Designing and building an appropriate monoclonal antibody plays an important role in creation of an APC complex. Today, the human IgG1 is used as an appropriate isotype to produce ADC, because it is able to stimulate both directions of ADCC (antibody-dependent cellular cytotoxicity) and CDC (complement-dependent cytotoxicity) [14-16].

Currently, many studies are being conducted on the use of antibody fragments in the ADC system.
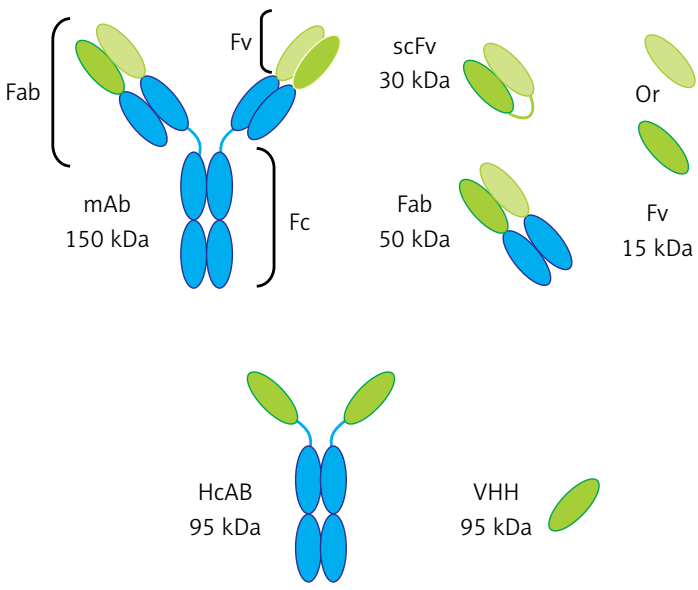

Figure 3. Different types of antibody fragments
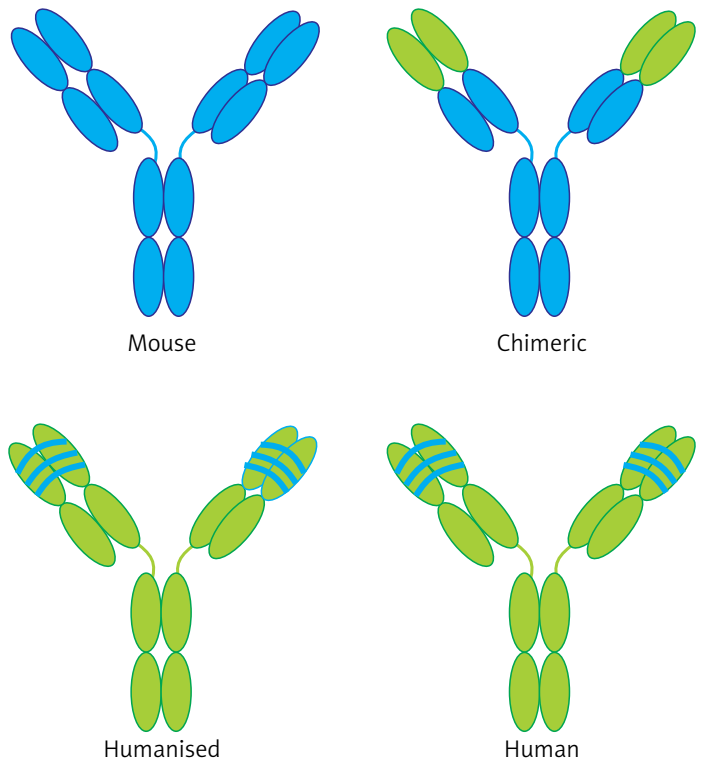

Figure 2. Different types of antibodies used

This type of antibody has a very good ability to penetrate into the tumor tissue due to its small size. Generally, the antibody fragments include FV, Fab, VHH and SCFV; these antibody fragments have conserved their binding properties to the antigen. When their size gets smaller, their structural complexity is reduced and thus they can be produced in cell cultures or even prokaryotic hosts such as Escherichia coli, which can be economically affordable. The nanobodies ( $\mathrm{VHH}$ ) have no $\mathrm{CH} 1$ domain but have a long CDR3. The longer $\mathrm{CH} 1$ due to forming a longer loop compared to others could have a conformation to detect many cancer epitopes placed in grooves and bind to them with a high specificity [17-21]. The nanobodies have a hydrophilic property with a higher solubility in water and resistance to denatured factors and temperature as well as having relatively high stability. The nanobodies can also be renatured after denaturation and do not aggregate even at higher

Table I. Different types of antigens against which to design antibodies

\begin{tabular}{|c|c|}
\hline \multicolumn{2}{|c|}{$\begin{array}{l}\text { Target antigens for ADCs in preclinical and clinical } \\
\text { development }\end{array}$} \\
\hline Cancer & Target antigens \\
\hline Breast & $\begin{array}{l}\text { CD174, GPNMB, CRIPTO and nectin-4 } \\
\text { (ASG-22ME) }\end{array}$ \\
\hline Ovarian & $\begin{array}{l}\text { MUC16 (CA125), TIM-1 (CDX-014) } \\
\text { and mesothelin }\end{array}$ \\
\hline Lung & $\begin{array}{l}\text { CD56, CD326, CRIPTO, FAP, mesothelin } \\
\text { and GD2 }\end{array}$ \\
\hline Pancreatic & $\begin{array}{c}\text { CD74, CD227 (MUC-1) and nectin-4 } \\
\text { (ASG-22ME) }\end{array}$ \\
\hline Prostate & PSMA, STEAP-1 and TENB2 \\
\hline
\end{tabular}


concentrations. The nanobodies are smaller than the kidney cut-off, so they are excreted through the kidneys, have a higher clearance, and cause lower toxicity in the body [22-24]. Different types of these antibodies are depicted in Figure 3.

An antigen chosen as a specific antigen of a cancer cell should adequately be expressed on the cell surface and have a low density on the normal cell surface to prevent binding of the APC complex to normal cells. Another characteristic of the chosen antigen is high capability of endocytosis induction when binding the antibody to it. Table I presents several examples of appropriate antigens for targeted placement by APCs.

However, the level of antigen expressed on the surface of target cells plays a significant role as a receptor in ADC efficiency, but numerous studies have proven that antigens expressed in low density on the surface of target cells have the power and the potential to be used in ADC [25-27]. For example, the CD33 receptor is expressed in low density $(5,000$ to 10,000$)$ on the surface of tumor cells in acute myeloid leukemia, but this receptor could successfully be used in a designed ADC named Mylotarg [28, 29].

Generally, the linker is categorized into two groups, cleavable and noncleavable. The cleavable linker group is divided into the following three groups: susceptible to proteolysis, susceptible to $\mathrm{pH}$, and susceptible to glutathione.

Linkers susceptible to proteolysis are cleaved through catB in the lysosome and cause release of the drug from the antibody. In fact, this type of linker has a valine-citrulline dipeptide bond, which is cleaved by cathepsin B within the lysosome and results in the release of drug. This type of linker is used in Adcetris, which is an ADC-based drug.

The second group comprises linkers that are susceptible to $\mathrm{pH}$. They are broken in low $\mathrm{pH}$ inside lysosomes and cause the release of the drug from the ADC complex. For example, hydrazone at $\mathrm{pH}=7$ is broken down after $183 \mathrm{~h}$ while it is decomposed in less than $5 \mathrm{~h}$ at $\mathrm{pH}$ 4.4. Because of the hypoxia of cancer cells, the $\mathrm{pH}$ level is low in these cells and this is an advantage of this type of linker. It is considerable that this type of linker could easily release at low $\mathrm{pH}$ and the drug may be released before entering the lysosome, so they are not usually suitable to build ADC complexes. Mylotarg can be mentioned as one of the drugs using this type of linker; the drug is released in the bloodstream due to the weakness of the linker and results in cytotoxic effects. That is why this drug was recollected from the markets.

The third group of cleavable linkers consists of linkers sensitive to concentrations of thiols such as glutathione; this type of linker is lysed inside cancer cells, which have high levels of glutathione, and then releases the drug. About noncleavable linkers, it should be noted that these linkers are more stable in the bloodstream, and currently are used in the drug Kadcyla [30-33].

Generally, two types of cytotoxic agent can bind to ADCs in order to treat cancer: microtubule inhibitors and DNA-damaging agents.

One of the factors to inhibit polymerization and depolymerization of microtubules is dolastatin, which is used in the drug Adcetris. Tubulysins are similar to auristatins and maytansine and induce apoptosis in cancer cells through inhibition of polymerization and depolymerization of microtubules. Auristatin is the third type of drug and is prepared from the sea hare Dolabella auricularia. Monometh$\mathrm{yl}$ auristatin $\mathrm{E}$ (MMAE), which is 1000 times more toxic than doxorubicin, is used in the drug Kadcyla.

Maytansinoids are the last type of drugs causing cell death by affecting microtubules, which are extremely toxic, and they can exhibit apoptotic properties at picogram levels and derive from the plant Maytenus.

Calicheamicin is one of the toxic agents that induce apoptosis by affecting the DNA structure. This toxin is derived from a native bacterium in Texas; it is 4,000 times more toxic than doxorubicin and causes DNA fragmentation by penetrating into a minor groove in DNA and thus cell death.

This toxin has been used in the drug Mylotarg. Duocarmycin also due to penetration into the DNA minor groove causes DNA fragmentation and cell death. Some of the drugs approved by the United States Food and Drug Administration (FDA) to date available in markets include Adcetris and Kadcyla. The full list of other drugs based on ADCs, which are in various stages of production, can be seen in Table II [34-36].

Controlled chemical reactions with specific amino acid residues exposed on the surface of the $\mathrm{mAb}$ are a part of the conjugation of the drug payload to the antibody according to previous trials on ADCs. As a result, some conjugation approaches have been investigated to decrease heterogeneity based on the creation of an ADC mixture with a different drug-to-antibody ratio (DAR) and linkage sites. The efficacy, PK and tolerability can be affected by choosing the proper method of drug conjugation within ADC design. Due to this reason, different conjugation technologies are warranted for ADC generation. Drug levels in circulation and the PK of the ADC can be under the influence of the number of drugs per antibody.

In general, the PK value is elevated by increasing the DAR level, the amount of PK is decreased by reducing the DAR level, and the decomposition level of ADC is reduced compared to the previous condition. Studies have clearly shown that the clearance level of blood is also altered by chang- 
Table II. Different types of drugs designed based on ADCs that are at different stages of clinical confirmation

\begin{tabular}{|c|c|c|c|c|}
\hline Agent & Linker & Warhead & Target & Phase \\
\hline IMMU-110 & Hydrazone & Doxorubicin & CD74 & 2 \\
\hline Mylotarg & Hydrazone & Calicheamicin & CD33 & Withdrawn \\
\hline CMC-544 & Hydrazone & Calicheamicin & CD22 & 3 \\
\hline SAR3419 & Disulfide & DM4 & CD19 & 2 \\
\hline BT-062 & Disulfide & DM4 & CD138 & 1 \\
\hline BAY-94-9343 & Disulfide & DM4 & Mesothelin & 1 \\
\hline SAR-566658 & Disulfide & DM4 & DS6 & 1 \\
\hline IMGN901 & Disulfide & DM1 & CD56 & 2 \\
\hline Kadcyla & Thioether & DM1 & HER2 & Licensed \\
\hline IMGN529 & Thioether & DM1 & CD37 & 1 \\
\hline SGN-75 & $M C$ & MMAF & CD70 & 1 \\
\hline Adcetris & Peptide (Val-Cit) & MMAE & CD30 & Licensed \\
\hline RG-7596 & Peptide (Val-Cit) & MMAE & CD79b & 2 \\
\hline CDX-011 & Peptide (Val-Cit) & MMAE & GPNMB & 2 \\
\hline PSMA-ADC & Peptide (Val-Cit) & MMAE & PSMA & 2 \\
\hline ASG-5ME & Peptide (Val-Cit) & MMAE & AGS-5 & 1 \\
\hline IMUU-130 & Peptide (Phe-Lys) & SN-38 & CEACAM5 & 2 \\
\hline
\end{tabular}

es in the DAR level, so that the plasma half-life is reduced and clearance of blood is increased by increasing DAR.

More favorable PK features have been found in ADCs with a DAR of 2-4, such as longer halflife, slower rate of clearance and greater efficacy, compared to more heavily loaded conjugates. The reduction in conjugate yield and the increase in heterogeneity in the average number of payload per antibody can be achieved by decreasing the DAR, so that a high level of antibody remains unconjugated when producing a DAR of two. However, there needs to be further research to elucidate the effect of conjugate site and stoichiometry on safety and efficacy of ADCs. The DAR only indicates the average payload per antibody.

Another effective factor for appropriate ADCs is the binding site of linker to antibody. Conjugation of linker to antibody is usually performed by binding to cysteine or lysine amino acids of antibodies each of which has its own specific properties.

Selection of the proper conjugation site is still challenging despite the availability of various improved techniques, resulting in significant heterogeneity in the conjugates. It should be noted that the payload distribution and unconjugated antibodies exist in the ADC products [37-40].

Several studies have proven that some ADCs not only are able to destroy target cells but also can eliminate the cells surrounding the tumor. The mechanism of this effect involves the diffusion of hydrophobic toxic molecules after separation from the antibody, which can be moved around the tumor cells to cause the death of tumor surrounding cells (bystander cells).

The reason for this transfer is the ability of hydrophobic toxic molecules to cross the bystander cell membranes, which have no target antigens on their cell surface. It should be noted that the bystander effect does not occur in drugs without the ability to pass through the cell membrane. Now the question that arises is whether this effect should be prevented or is useful for treatment of cancer. Given that the cells in the tissue surrounding the tumor cells play a role in feeding and supporting these cells, the bystander effect by removing these feeding cells can have an effective role in the treatment of cancer [41-43].

Although at first glance it seems simple to make drugs based on ADCs, in practice combination of three parts of ADCs and optimization of each of them that could be used in cancer treatment is a difficult and complex process so that, to date, only three drugs have been introduced to the markets with authorization from the FDA.

Gemtuzumab ozogamicin with the Mylotarg brand was the first drug approved by the FDA for the treatment of acute myeloid leukemia (AML) 
disease. In 2010, almost 10 years after the sale of this drug on the global markets, a clinical trial was conducted on this drug. The results of this study showed that not only does the therapeutic effect of Mylotarg have no significant difference in treatment of cancer compared to traditionally used drugs, but also it has serious toxic effects on the liver. Therefore, the FDA revoked permission for production and sale of the drug and it was recollected from around the world. This phenomenon was due to the fact that the linker used in the ADCs was not stable enough and the drug is separated from ADCs in the bloodstream [44-46].

The FDA under accelerated approval regulations in 2011 introduced brentuximab vedotin as the first ADC. This drug was introduced to the market with the Adcetris brand for the treatment of Hodgkin's lymphoma. Each Adcetris contains about four auristatin molecules (MMAE) that are linked to a human chimeric monoclonal antibody molecule of anti-CD30 lgG1 via a peptide linker sensitive to valine-citrulline. After binding of ADC to the CD30 molecule, it is internalized into cells quickly and moves towards the lysosomes where the linkage between the drug and the antibody is broken. Then monomethyl auristatin $\mathrm{E}$ is released into the cells and induces termination of the cell cycle between the $G 2$ and $M$ phases by binding to tubulins and thus cell apoptosis. The dosage used for the treatment is $1.8 \mathrm{mg} / \mathrm{kg}$, which is intravenously injected for 3 weeks $[47,48]$.

The FDA and the European Medicines Agency (EMA) suggested it (with Kadcyla brand) to employ in advance breast cancer in February 2013 and November 2013, respectively.

This drug contains DM1 that is bound to HER2 monoclonal antibody by a thioether bond. This drug is used for treatment of $\mathrm{HER}^{+}$metastatic breast cancer in patients who have been previously treated with trastuzumab or taxane or both. The drug Kadcyla causes disappearance of the tumor cells by inhibiting microtubule function. The dosage used for treatment is $3.6 \mathrm{mg} / \mathrm{kg}$, and it is intravascularly injected every 3 weeks $[49,50]$.

Currently, although only these two drugs are available on the market, over 30 other drugs have been made based on ADCs for cancer treatment. Several types of these drugs that are in different phases of testing are listed in Table II [51-53].

In conclusion, cancer treatments by traditional methods cause undesirable side effects in the body due to the effects of chemotherapeutic drugs on normal cells, but the use of ADCs could lead to apoptosis of cancer cells by targeted drug delivery. The ADC complex consists of an antibody specific to a cancer cell. This antibody has been bonded to a cytotoxic agent (anti-cancer drug) via a linker. The ADCs deliver the anti-cancer drug into the targeted cancer cells to induce apoptosis.
However, there are still many factors to study in improving performance of ADC complexes, such as choosing the cancer antigen, preparing specific monoclonal antibodies and particularly the type of chosen linker and cytotoxic agent. Given the wide range of research about the development of drug delivery systems based on ADCs, there is hope to provide effective drugs for treatment of cancer in the future by improving the mentioned factors.

\section{Conflict of interest}

The authors declare no conflict of interest.

\section{References}

1. Schwartz RS. Paul Ehrlich's magic bullets. N Engl J Med 2004; 350: 1079-80.

2. Strebhardt K, Ullrich A. Paul Ehrlich's magic bullet concept: 100 years of progress. Nat Rev Cancer 2008; 8: 473-80.

3. Winau F, Westphal O, Winau R. Paul Ehrlich - in search of the magic bullet. Microbes Infect 2004; 6: 786-9.

4. Ornes S. Antibody-drug conjugates. Proc Natl Acad Sci USA 2013; 110: 13695.

5. Zolot RS, Basu S, Million RP. Antibody-drug conjugates. Nat Rev Drug Discov 2013; 12: 259-60.

6. Alley SC, Okeley NM, Senter PD. Antibody-drug conjugates: targeted drug delivery for cancer. Curr Opin Chem Biol 2010; 14: 529-37.

7. Sapra P, Allen TM. Internalizing antibodies are necessary for improved therapeutic efficacy of antibody-targeted liposomal drugs. Cancer Res 2002; 62: 7190-4.

8. Xu S. Internalization, trafficking, intracellular processing and actions of antibody-drug conjugates. Pharm Res 2015; 32: 3577-83.

9. Austin CD, Wen X, Gazzard L, Nelson C, Scheller RH, Scales SJ. Oxidizing potential of endosomes and lysosomes limits intracellular cleavage of disulfide-based antibody-drug conjugates. Proc Natl Acad Sci USA 2005; 102: 17987-92.

10. Bareford LM, Swaan PW. Endocytic mechanisms for targeted drug delivery. Adv Drug Deliv Rev 2007; 59: 748-58.

11. Cho K, Wang X, Nie S, Shin DM. Therapeutic nanoparticles for drug delivery in cancer. Clin Cancer Res 2008; 14: 1310-6.

12. Nimmerjahn F, Ravetch JV. Analyzing antibody-Fc-receptor interactions. Methods Mol Biol 2008; 415: 151-62.

13. Vidarsson G, Dekkers G, Rispens T. IgG subclasses and allotypes: from structure to effector functions. Front Immunol 2014; 5: 520.

14. Almagro JC, Fransson J. Humanization of antibodies. Front Biosci 2008; 13: 1619-33.

15. Birch JR, Racher AJ. Antibody production. Adv Drug Deliv Rev 2006; 58: 671-85.

16. Khazaeli M, Conry RM, LoBuglio AF. Human immune response to monoclonal antibodies. J Immunother 1994; 15: 42-52.

17. Nelson AL. Antibody fragments: hope and hype. In: MAbs; 2010: Taylor \& Francis; 2010; 77-83.

18. Hudson PJ, Souriau C. Engineered antibodies. Nat Med 2003; 9: 129-34.

19. Holliger P, Hudson PJ. Engineered antibody fragments and the rise of single domains. Nat Biotechnol 2005; 23: 1126-36. 
20. Flanagan RJ, Jones AL. Fab antibody fragments. Drug safety 2004; 27: 1115-33.

21. Ahmad ZA, Yeap SK, Ali AM, Ho WY, Alitheen NBM, Hamid M. scFv antibody: principles and clinical application. Clin Dev Immunol 2012; 2012: 980250.

22. Hassanzadeh-Ghassabeh G, Devoogdt N, De Pauw P, Vincke C, Muyldermans S. Nanobodies and their potential applications. Nanomedicine 2013; 8: 1013-26.

23. Muyldermans S. Nanobodies: natural single-domain antibodies. Ann Rev Biochem 2013; 82: 775-97.

24. Oliveira S, Heukers R, Sornkom J, Kok RJ, en Henegouwen PMvB. Targeting tumors with nanobodies for cancer imaging and therapy. J Control Release 2013; 172: 607-17.

25. Diamantis N, Banerji U. Antibody-drug conjugates - an emerging class of cancer treatment. $\mathrm{Br}$ J Cancer 2016; 114: 362-7.

26. Thomas A, Teicher BA, Hassan R. Antibody-drug conjugates for cancer therapy. Lancet Oncol 2016; 17: e254-62.

27. Trail PA. Antibody drug conjugates as cancer therapeutics. Antibodies 2013; 2: 113-29.

28. Stasi R. Gemtuzumab ozogamicin: an anti-CD33 immunoconjugate for the treatment of acute myeloid leukaemia. Exp Opin Biol Ther 2008; 8: 527-40.

29. Pagano L, Fianchi L, Caira M, Rutella S, Leone G. The role of gemtuzumab ozogamicin in the treatment of acute myeloid leukemia patients. Oncogene 2007; 26: 3679-90.

30. Donaghy $\mathrm{H}$. Effects of antibody, drug and linker on the preclinical and clinical toxicities of antibody-drug conjugates. In: mAbs; 2016: Taylor \& Francis 2016; 659-71.

31. Gébleux R, Casi G. Antibody-drug conjugates: current status and future perspectives. Pharmacol Therap 2016 167: 48-59.

32. Kolakowski RV, Haelsig K, Jeffrey S, Senter P. A nove linker to enable alcohol-containing payloads for the preparation of antibody-drug conjugates. Cancer Res 2016; 76: 4334-4.

33. Tsuchikama K, An Z. Antibody-drug conjugates: recent advances in conjugation and linker chemistries. Protein Cell 2018; 9: 33-46.

34. Adem YT, Schwarz KA, Duenas E, Patapoff TW, Galush WJ, Esue O. Auristatin antibody drug conjugate physical instability and the role of drug payload. Bioconjug Chem 2014; 25: 656-64.

35. Lambert JM. Drug conjugated antibodies for the treatment of cancer. Br J Clin Pharmacol 2013; 76: 248-62

36. Tan C. Payloads of antibody-drug conjugates. In: Antibody-Drug Conjugates. Wang J, Shen WC, Zaro JL (eds.) Springer 2015; 11-22.

37. Erickson HK, Lambert JM. ADME of antibody-maytansinoid conjugates. AAPS J 2012; 14: 799-805.

38. Xu K, Liu L, Dere R, et al. Characterization of the drug-to-antibody ratio distribution for antibody-drug conjugates in plasma/serum. Bioanalysis 2013; 5: 1057-71.

39. Lin K, Tibbitts J. Pharmacokinetic considerations for antibody drug conjugates. Pharm Res 2012; 29: 2354-66.

40. Lin K, Tibbitts J, Shen BQ. Pharmacokinetics and ADME characterizations of antibody-drug conjugates. Methods Mol Biol 2013; 1045: 117-131.

41. Kovtun YV, Goldmacher VS. Cell killing by antibody-drug conjugates. Cancer Lett 2007; 255: 232-40.

42. Ogitani Y, Hagihara K, Oitate $M$, Naito $H$, Agatsuma T. Bystander killing effect of DS-8201a, a novel anti-HER2 antibody-drug conjugate, in tumors with HER2 heterogeneity. Cancer Sci 2016; 107: 1039-46.

43. Singh AP, Sharma S, Shah DK. Quantitative characterization of in vitro bystander effect of antibody-drug conjugates. J Pharmacokinet Pharmacodynam 2016; 43: 567-82.

44. Peipp M, Gramatzki M. Gemtuzumab Ozogamicin (Mylotarg). In: Handbook of Therapeutic Antibodies. Dubel S (ed.). Wiley 2007; 869-83.

45. Ravandi F, Estey EH, Appelbaum FR, et al. Gemtuzumab ozogamicin: time to resurrect? J Clin Oncol 2012; 30: 3921-3

46. Zaro JL. Mylotarg: revisiting its clinical potential postwithdrawal. In: Antibody-Drug Conjugates. Wang J, Shen WC, Zaro JL (eds.). Springer 2015; 179-90.

47. Gardai SJ, Epp A, Law CL. Brentuximab vedotin-mediated immunogenic cell death. Cancer Res 2015; 75: 2469.

48. Younes A, Yasothan U, Kirkpatrick P. Brentuximab vedotin. Nat Rev Drug Discov 2012; 11: 19-20.

49. Boyraz B, Sendur MA, Aksoy S, et al. Trastuzumab emtansine (T-DM1) for HER2-positive breast cancer. Curr Med Res Opin 2013; 29: 405-14.

50. Burris HA, Tibbitts J, Holden SN, Sliwkowski MX, Phillips GDL. Trastuzumab emtansine (T-DM1): a nove agent for targeting HER2+ breast cancer. Clin Breast Cancer 2011; 11: 275-82.

51. Polakis P. Antibody drug conjugates for cancer therapy. Pharmacol Rev 2016; 68: 3-19.

52. Senter PD. Potent antibody drug conjugates for cancer therapy. Curr Opin Chem Biol 2009; 13: 235-44

53. Tolcher A. Antibody drug conjugates: lessons from 20 years of clinical experience. Ann Oncol 2016; 27: 2168-72. 